\title{
As Novas Perspectivas da Gestão de Pessoas nas Indústrias do Polo Calçadista de Juazeiro do Norte-Ceará
}

\author{
Maria Aparecida Trajano de Sousa ${ }^{1}$; Sabina Michelle de Matos Cavalcante ${ }^{2}$; \\ José Leandro de Almeida Neto ${ }^{3}$
}

\begin{abstract}
Resumo: O presente artigo discorre sobre a Gestão de Recursos Humanos, sendo apresentado seu histórico e conceito, deixando clara a diferença entre a gestão de pessoas, onde se desenvolve com os seus seis subsistemas e processos, sendo eles: Provisão, Aplicação, Manutenção, Desenvolvimento, Compensação e Monitoração e só departamento de pessoal, ligada a parte burocrática da empresa, baseada em folha de pagamento, $13^{\circ}$ salário, férias e etc. Em relação a esses conceitos, amplia-se o conteúdo atribuído a este setor dentro das indústrias calçadista caririense. Assim sendo, este trabalho visa identificar a estrutura e funcionamento do setor de recursos humanos no pólo calçadista de Juazeiro do Norte-CE. A metodologia da pesquisa utilizada foi de caráter exploratório e descritivo, sendo escolhido o método quali-quanti. Com base na pesquisa realizada em seis empresas do segmento, observa-se que as mesmas visam os recursos humanos como um investimento necessário para o sucesso da organização, ressaltando a desqualificação de profissionais para colocar esse setor em prática.
\end{abstract}

Palavras-chave: Cariri, Gestão de Pessoas, Pólo Calçadista.

\section{The New Perspectives of People Management in the footwear "polo" industries of Juazeiro do Norte - Ceará}

\begin{abstract}
This article discusses the Human Resource Management, and presented their history and concept, making clear the difference between managing people, where it develops with its six subsystems and processes, as follows: Provision, Application Maintenance, Development, compensation and Monitoring, and only personnel department, linked the paperwork of the company, based on payroll, 13th salary, vacation and etc.. In relation to these concepts, expands content assigned to this sector within industries caririense footwear. Therefore, this study aims to identify the structure and functioning of the human resources sector in the shoe industry in Juazeiro do Norte, CE. The research methodology used was exploratory and descriptive, being chosen the qualitative and quantitative method. Based on research conducted in six companies in the industry, it is observed that the same target human resources as a necessary investment for the organization's success, highlighting the disqualification of industry professionals to put that into practice.
\end{abstract}

Keywords: Cariri, People Management, Polo Footwear.

\section{Introdução}

O Pólo Calçadista Caririense surgiu há quarenta anos, com base na demanda brasileira por sandálias de verão. Neste contexto, algumas empresas da cidade de Juazeiro do Norte-CE resolveram iniciar a fabricação destes produtos.

\footnotetext{
${ }^{1}$ Graduandos do Curso de Tecnologia em Gestão de Recursos Humanos da Faculdade Leão Sampaio. E-mail: michellecavalcante2012@ hotmail.com; aparecidatrajano2012@hotmail.com.

${ }^{2}$ Professor Orientador. Graduado em Administração, Especializado em Gestão Estratégica do Capital Humano e Docência do Ensino Superior.. E-mail: leandro@leaosampaio.edu.br.
} 
Com o tempo, a atividade se expandiu e hoje existem mais de 300 indústrias funcionando no município desde pequenas, médias e grandes organizações, empregando mais de 16 mil pessoas. A Região do Cariri é consolidada como um grande centro da indústria de calçados nacional, sendo que a cidade de Juazeiro do Norte vem se destacando cada vez mais, onde seu complexo industrial abriga o maior Polo Produtor do Norte e Nordeste, estando classificado como o $3^{\circ}$ maior do Brasil, conforme dados publicados em 2011 no site Sindindustria.

Considerando essa conjuntura e levando principalmente em consideração o tamanho deste setor, decidiu-se realizar uma pesquisa científica para constatar como se encontra o departamento de Gestão de Pessoas nessas organizações, se as empresas dispõem desse setor estruturado e qual a visão dos empreendedores em relação á área.

Acredita-se que a maioria das empresas do segmento não dispõe de um departamento de Recursos Humanos estruturado, ou algum profissional específico para este setor, o que poderá indicar uma carência de investimento nessa área. Talvez esse investimento não ocorra devido algumas organizações não terem uma visão ampla da importância da área, apenas visando o custo e deixando de avaliar o benefício que trará para os colaboradores e o retorno que será de grande valia para empresa.

O projeto de pesquisa tem como principal objetivo identificar a estrutura e funcionamento do setor de recursos humanos no polo calçadista de Juazeiro do Norte-CE. De maneira mais específica, descrever como está sendo implantado o setor de recursos humanos nessas organizações, verificar dados quanto ao funcionamento do setor que possam apresentar objetivamente a importância e desenvolvimento da gestão de pessoas dentro das indústrias calçadistas, bem como analisar em toda sua conjuntura se utilizam com os 06 subsistemas, sendo de: provisão, aplicação, manutenção, desenvolvimento, compensação e monitoração na gestão de pessoas.

O tema abordado identifica a necessidade de uma estrutura de Recursos Humanos ativa, levando em consideração os grandes benefícios e resultados para as organizações e colaboradores.

A pesquisa apresentará dados como uma contribuição para os empreendedores do segmento calçadista, visto que esses empregadores devem possuir uma nítida consciência das diferentes formas de transformações, para que através dessa percepção despertem o desejo de quebrar velhos paradigmas e se enquadrar nesse novo sistema de administrar, gerando entre outros, informações principalmente aos que estão engajados no curso de Gestão de Recursos Humanos, onde terão uma visão maior de como se encontra o mercado de trabalho no Pólo Calçadista.

Esta pesquisa caracteriza-se como bibliográfica. Quanto aos objetivos, classifica-se como exploratória e descritiva, mediante a execução dos mesmos. A pesquisa caracteriza-se ainda como quali-quanti, pois, o estudo visa colher dados e amostras de levantamentos numéricos e tratamento 
http://idonline.emnuvens.com.br/id

ISSN on-line: 1981-1179

estatístico. Trata-se de uma pesquisa de campo, na qual foi utilizada entrevista estruturada com profissionais das indústrias que se enquadram na proposta dos objetivos.

Conforme questionário aplicado aos gestores do setor calçadista da cidade de Juazeiro do Norte-CE, conclui-se que a maioria dos empreendedores diz dispor da área de recursos humanos ativa, onde $50 \%$ dos entrevistados afirmam que os processos de gestão de pessoas são efetuados por profissionais da área.

\section{História e Conceito da Gestão de Recursos Humanos}

O departamento de recursos humanos (RH) de uma empresa exerce um papel de suma importância, pois é o elo entre os empregadores e seus colaboradores.

Chiavenato (2009) conceitua que a gestão de recursos humanos tem a capacidade de envolver inúmeros conceitos de várias áreas, por tratar diretamente com o ser humano, ou seja, indivíduos com personalidades diferentes, pois as organizações são constituídas por pessoas e dependem delas para alcançar seus objetivos e cumprir suas missões, o que requer do profissional da área de $\mathrm{RH}$ experiência e um bom volume de conhecimentos.

A administração de recursos humanos (ARH) é o ramo especializado da ciência da administração que envolve todas as ações que tenham como objetivo a interação do trabalhador no contexto da organização e o aumento de sua produtividade. É uma área interdisciplinar e tem como função enfatizar a importância dos funcionários, dando subsídios para que estes se desenvolvam na organização, realizando seus objetivos profissionais e ao mesmo tempo auxiliando a empresa a alcançar suas metas.

Chiavenato (2009) descreve que ARH é composta por cinco subsistemas interdependentes, sendo eles os subsistemas de: provisão, aplicação, manutenção, desenvolvimento e monitoração, neste contexto são apresentados o que representa cada processo.

\section{Os subsistemas e seus processos}

Os subsistemas da gestão de recursos humanos segundo Chiavenato 2010 são:

- Processos de Agregar Pessoas: São os processos utilizados para agregar novas pessoas na empresa, incluem Pesquisa de mercado de $\mathrm{Rh}$, recrutamento e seleção de pessoas.

Id en line Revista de Psicologia. Ano 7, No. 21, Novembroo/2013 - ISSN 1981-1179.

Edição eletrônica em http://idonline.emnuvens.com.br/id 
- Processos de Aplicar Pessoas: São os processos utilizados para desenhar as atividades que as pessoas irão desempenhar na empresa. Incluem integração de pessoas, desenho de cargos, descrição e análise de cargos, orientação das pessoas e avaliação de desempenho.

- Processos de Recompensar Pessoas: São os processos para incentivar as pessoas. Incluem remuneração e compensação, benefícios e serviços sociais.

- Processos de Desenvolver Pessoas: São os processos de utilizados para capacitar o desenvolvimento pessoal e profissional das pessoas. Envolvem treinamento, desenvolvimento organizacional, programas de mudanças.

- Processos de Manter Pessoas: São os processos utilizados para criar condições ambientais e psicológicas das pessoas. Incluem administração da cultura organizacional, clima, disciplina, higiene e qualidade de vida.

- Processos de Monitorar Pessoas: São os processos utilizados para acompanhar e controlar as pessoas. Incluem banco de dados, sistemas de informações gerais.

Segundo Silva (2009), todos esses processos e subsistemas estão ligados estre si, de tal maneira que um influencia o outro. Todos são executados de acordo com as influências ambientais externas (leis e sindicatos), condições econômicas, políticas, sociais, culturais e competitivas, como também das influências organizacionais internas (missão, visão organizacional, objetivos e estratégias, estilo de liderança, entre outros), para que haja melhor harmonização entre eles.

Chiavenato (2009) destaca que ARH teve origem no início do século XX, surgiu a partir da complexidade das empresas após o forte impacto da Revolução Industrial, originou-se com o objetivo de abrandar os conflitos entre os objetivos organizacionais e os objetivos individuais das pessoas. Em meados da década de 1950, passou a ser denominada Administração de Pessoal. Já não se tratava apenas de intermediar os desentendimentos e reduzir os conflitos, mas, sobretudo, administrar as pessoas segundo a legislação trabalhista vigente e administrar os conflitos que surgissem.

Pouco tempo depois em meados da década de 1960, o conceito teve nova ampliação, as pessoas passaram a serem considerados os recursos fundamentais para o sucesso organizacional, aliás, os únicos recursos vivos e inteligentes que as organizações dispunham para enfrentar os desafios pela frente. Assim, surgiu o conceito Administração de Recursos Humanos. (IBIDEM)

Com um contexto globalizado e o mundo fortemente competitivo, onde impera a intensa inovação tecnológica e expansão de mercado na busca pelo seu crescimento, a tendência que se nota nas organizações bem-sucedidas é de não mais administrar recursos humanos, nem mais administrar as pessoas, mas, sobretudo, administrar com as pessoas.

A gestão de pessoas no cenário atual é fundamental para a sobrevivência de qualquer negócio, pois experimente comparar o antes e o depois de uma empresa que não realizava práticas de gestão de 
pessoas e passou a fazer isso. Certamente serão observadas mudanças, desde a produtividade até a satisfação e motivação dos funcionários.

\section{Estratégias da Gestão De Recursos Humanos}

Historicamente conhecida como Administração de Pessoal, a área de Recursos Humanos é responsável, de modo bem genérico, por administrar as pessoas dentro da organização. A área surgiu da necessidade de controlar as pessoas que trabalhavam na organização, inicialmente em aspectos muito simples como horas de trabalhos, faltas e salários. Dede seu surgimento aos dias de hoje, a área foi ganhando inúmeras atividades, bem como maiores responsabilidades e maior importância para o sucesso da organização. Pode-se dizer que a área foi passando de operacional para estratégica.

A área de Recursos Humanos deixou de ser um mero departamento de pessoal para se tornar o personagem principal de transformação dentro da organização. Há pouco tempo atrás, o departamento de Recursos Humanos esteve voltado para a defesa da postura do poder, onde os principais objetivos a serem atingidos eram disciplina e ordem.

Ao longo dos tempos o processo de contratar e demitir pessoas sofreu relevantes mudanças em sua base, deixando de lado o termo funcionário e passando adotar o termo colaborador, saindo de um regime de portas fechadas e entrando em outro regime de portas abertas. (BAZE, 2010, p.1).

Nesse pensamento observa-se que as pessoas passaram a ter uma maior importância dentro das organizações, hoje o cenário é diferente, os empregados são chamados de colaboradores e os chefes de gestores. A gestão de pessoas visa à valorização dos profissionais e do ser humano, adequando as necessidades da empresa a disponibilidade do funcionário.

O profissional de $\mathrm{Rh}$ ainda é um executivo encontrado somente nas grandes organizações e, excepcionalmente, nas médias organizações. Toda via, a ARH é perfeitamente aplicável a qualquer tipo ou tamanho de organização. Lidar com pessoas faz parte integrante do núcleo de desafios de uma organização. (CHIAVENATO 2009, p.251)

Algumas empresas ainda conservam antigas formas de visão dos seus recursos humanos, tratando-os como custos fixos, deixando de observar que a gestão de pessoas, assume cada vez mais a importância no desenvolvimento de uma cultura organizacional, direcionado para a inovação e aprendizagem contínua, desempenhando um papel fundamental no nível externo e interno, provocando alterações nas estruturas organizacionais, nas relações de poder e nas práticas direcionadas ao trabalho.

Id en line Revista de Psicologia. Ano 7, No. 21, Novembroo/2013 - ISSN 1981-1179. Edição eletrônica em http://idonline.emnuvens.com.br/id 
Baseados nessas informações e nos constantes desafios interpostos pelo mundo moderno surgem organizações proativas, velozes, capazes de interagir com o seu ambiente externo e interno, são apresentadas as técnicas de Recursos Humanos do ambiente interno e externo de uma organização.

Quadro 01: Técnicas de ARH

\begin{tabular}{|c|c|}
\hline \multicolumn{2}{|c|}{$\begin{array}{l}\text { TÉCNICAS DE ARH COM O AMBIENTE EXTERNO E INTERNO DE UMA } \\
\text { ORGANIZAÇÃO }\end{array}$} \\
\hline $\begin{array}{l}\text { TÉCNICAS UTILIZADAS NO AMBIENTE } \\
\text { EXTERNO }\end{array}$ & $\begin{array}{l}\text { TÉCNICAS UTILIZADAS NO } \\
\text { AMBIENTE INTERNO }\end{array}$ \\
\hline${ }^{\circ}$ Pesquisa de mercado de Recursos Humanos & ${ }^{\circ}$ Análise e descrição de cargos \\
\hline${ }^{\circ}$ Recrutamento e seleção & ${ }^{\circ}$ Avaliação de cargos \\
\hline${ }^{\circ}$ Pesquisa de salários e benefícios & ${ }^{\circ}$ Treinamento \\
\hline${ }^{\circ}$ Relações com sindicatos & ${ }^{\circ}$ Avaliação de desempenho \\
\hline${ }^{\circ}$ Relações com entidade de formação profissional & ${ }^{\circ}$ Plano de carreiras \\
\hline \multirow[t]{3}{*}{${ }^{\circ}$ Legislação trabalhista etc. } & ${ }^{\circ}$ Plano de benefícios sociais \\
\hline & ${ }^{\circ}$ Política salarial \\
\hline & ${ }^{\circ}$ Higiene e segurança etc. \\
\hline
\end{tabular}

Fonte: Chiavenato (2007, p.252).

Para (BIANCHI; ALBUQUERQUE, 2004, p. 4) além de perceber e compreender o ambiente externo e suas demandas, as organizações devem se posicionar para enfrentá-lo. O posicionamento das organizações está relacionado à estratégia.

Não existe um único significado para a palavra estratégia, mas a definição feita por Albuquerque (2002), apud Bianchi; Albuquerque, (2004, p. 4) na qual "Estratégia é a formulação da missão e dos objetivos da organização, bem como de políticas e planos de ação para alcançá-los, considerando os impactos das forças ao ambiente e a competição" é bem objetiva e completa.

Olhar para o ambiente externo significa compreender os processos e alinhar as necessidades organizacionais a seus objetivos específicos. Criar planos de ação que permita estabelecer a direção e a competência é fundamental para a realização do que a empresa se propõe a alcançar, reforçando a necessidade de resultados empresariais.

O termo administração estratégica está relacionada em definir o que se quer alcançar dentro da instituição e traçar uma visão sistémica nas quais definem a busca para realização dos objetivos propostos. 


\section{Como implantar a Gestão de Pessoas em uma Organização}

Stock (2009) ressalta que compete ao departamento de recursos humanos promover, planejar, coordenar e controlar as atividades desenvolvidas relacionadas à seleção, orientação, avaliação de desempenho funcional e comportamental, capacitação, qualificação, acompanhamento do pessoal da instituição num todo, assim como as atividades relativas à preservação da saúde e da segurança no ambiente de trabalho da Instituição.

O setor de gestão de pessoas tem uma grande responsabilidade na formação do profissional que a instituição deseja, objetivando o desenvolvimento e crescimento da instituição como o do próprio funcionário, tido como colaborador para adquirir os resultados esperados.

A importância do planejamento, controle e condução do processo de gestão de pessoas é de extrema importância também em pequenas organizações, pois elas também são compostas de colaboradores, pessoas com necessidades, com anseios e expectativas de crescimento e desenvolvimento profissional.

O sistema de gestão de RH tem por missão estruturar-se de tal forma que permita à organização aumentar o valor que o seu capital humano agrega ao negócio, reter os talentos críticos para o presente e futuro do negócio, desenvolver as habilidades para cumprir as estratégias de curto e longo prazo. (CARVALHO; SEIXAS, 2012, p.1).

Lidar com pessoas representa um dos maiores desafios dos gestores, conduzi-las na direção citada é um trabalho complexo, que envolve mudanças profundas em toda a organização que só se efetivam no longo prazo, os gestores de RH tendem a enfrentar e superar de forma racional e eficiente os inúmeros e crescentes desafios em termos de gestão e retenção de pessoas. Neste sentido, preparar a organização para este futuro implica em estimular processos de mudanças.

Para (CARVALHO; SEIXAS, 2012) para iniciar a implantação do sistema de Recursos Humanos, é necessário discutir estrategicamente como a empresa está sendo afetada pela falta de um modelo de gestão de RH estruturado. O intuito dessa reflexão é analisar as práticas existentes e quais procedimentos devem compor o novo modelo de gestão, na qual irá orientar o estilo de atuação dos gestores e sua relação com a equipe para alcance dos resultados.

Para Salles (2009), de todos os processos e ferramentas de gestão de recursos humanos conhecidos, o mais importante é discutir onde a empresa deseja chegar. Avaliar e descrever cargos, analisar desempenho, capacitação e perfil psicológico, pesquisar de satisfação e clima organizacional, entre outros. Neste sentido, é necessário um gestor de rh capaz de absorver novas ideias e aplicar no seu campo de trabalho, interpretar e colocar em prática os resultados apurados a partir da amostra analisada, por outro lado é preciso uma empresa flexível, aberta a mudanças e inovações. 
A gestão de RH nas pequenas empresas é fundamental para o sucesso do negócio, vender essa ideia para diretores e lideres é o primeiro passo. Segue um roteiro simples de ações que devem ser estruturadas e planejadas, para que aos poucos sejam implantadas nas empresas. De acordo com (STOCK, 2009):

\section{Quadro 2: Implantar o RH em uma organização.}

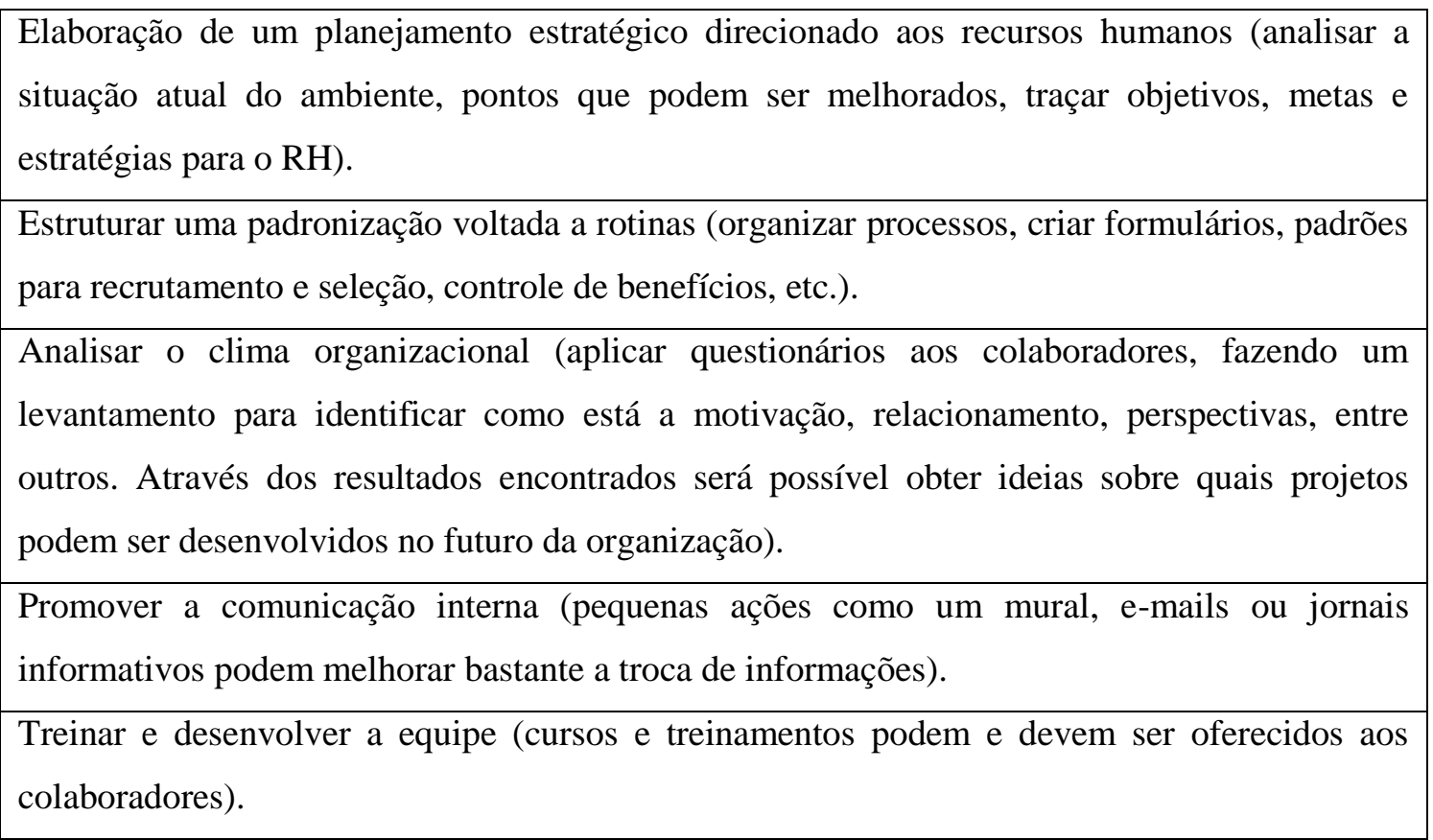

Fonte: quadro adaptado Stock (2009).

Essas práticas e políticas devem estar a serviço da estratégia da empresa, devem representar a realidade da organização e os objetivos que espera alcançar. Depois, será necessário definir a estrutura organizacional de RH de forma a garantir o sucesso na implantação do modelo estabelecido. Para isso deve-se olhar com atenção para as pessoas, objetivos, processos, estrutura e para as formas de incentivo da empresa como ponto de partida as estratégias adotadas.

Portanto, pode-se perceber o processo desafiador que a área de Recursos Humanos tem que exercer nas organizações: o papel de parceiro estratégico do negócio. Este movimento pede um sistema de gestão de Recursos Humanos efetivos e que pequenas práticas, como as citadas acima, possam trazer mudanças significativas para melhorar o desemprenho dos colaboradores, bem como transformar o clima e a cultura organizacional.

Gestão de pessoas envolve criatividade, argumentação e inovação, pois somente assim será possível manter os talentos que proporcionam o sucesso da empresa, garantindo assim resultados consistentes. 
Segundo recente pesquisa Publicada (Deloitte sobre os Desafios e Planos de Investimento do Empresariado Brasileiro até 2015), Recursos Humanos aparece em segundo lugar como destino dos novos investimentos de acordo com $68 \%$ dos participantes. Portanto ter um sistema de gestão de RH é fundamental para garantir transparência e sustentabilidade para os negócios bem como um retorno mais efetivo sobre este investimento.

Mas não se engane esse processo não ocorre da noite para o dia, é necessário paciência, perseverança e objetividade. Todos os líderes da empresa devem acreditar no serviço que o RH pode oferecer e nas mudanças positivas que isso trará a organização. (STOCK, 2009).

O processo de implementação do Departamento de Recursos humanos nas empresas, requer muito mais que investimentos, é preciso ter pessoas capacitadas, dotadas de talentos, habilidades e que sejam profissionais da área, porém é preciso ter maior flexibilidade e resiliência, pois o profissional da área de recursos humanos terá que lidar com situações onde precisará implementar projetos e processos, onde algumas vezes a diretoria, ou a liderança do setor não irá concordar com essas mudanças.

\section{Método}

Esta pesquisa caracteriza-se como bibliográfica, que segundo (GIL, 2002, p.44) "é desenvolvida com base em material já elaborado, constituído principalmente de livros e artigos científicos".

Quanto aos objetivos, para Gil (2002) classifica-se como exploratória, pois aprimorará as ideias colhidas no estudo e descritiva, mediante utilização de técnicas padronizadas de dados, como questionários que serão abordados e analisados.

A pesquisa caracteriza-se ainda como quali-quantitativa que para (LAKATOS; MARCONI, 2011), o estudo preocupa-se em analisar e interpretar aspectos mais detalhados, bem como colher amostras de levantamentos numéricos e tratamento estatístico.

Trata-se ainda de uma pesquisa de campo, que para Lakatos; Marconi, (2010, p.169) "é aquela utilizada com objetivo de conseguir informações e/ou conhecimentos a cerca de um problema, para qual se procura uma resposta que se queira comprovar".

Desta forma pode-se dizer que a pesquisa de campo, contribui para que o pesquisador se aprofunde na área, relacionando os assuntos provenientes do estudo com os dados coletados.

Em relação ao meio utilizado, foi realizada uma pesquisa em seis indústrias de calçados, na cidade de Juazeiro do Norte-CE, cujo questionário foi de estrutura subjetiva, os mesmos analisados de 
forma qualitativa e quantitativa. A aplicação do questionário foi realizada entre os dias um e quatro de Junho de dois mil e treze, tendo como participantes seis pessoas do nível estratégico.

\title{
Análise e Discussão dos Resultados
}

Essa seção tem por objetivo detalhar e organizar os dados coletados no transcorrer da pesquisa a fim de responder ao objetivo proposto. Onde se separa por partes, sendo a primeira voltada ao porte da empresa e perfil do gestor e a segunda parte refere-se aos resultados da pesquisa.

Observa-se que das empresas entrevistadas duas são empresas individuais, ou seja, de um único proprietário, como também duas são empresas de pequeno porte e duas empresas de médio porte, onde a maioria está atuando no mercado entre há seis anos e empregando de um a cinquenta e cinco funcionários.

Pode-se perceber que os gestores tem entre dezoito e quarenta e oito anos, onde foi constatado que a maioria possui um grau de escolaridade superior e com salários mensais entre três e seis salários mínimos.

\section{Resultados do questionário aplicado aos empreendedores.}

Gráfico 1: Visão do empreendedor em relação aos recursos humanos da empresa

\section{VISÃO DO RH NAS EMPRESAS}

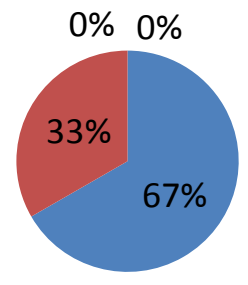

\author{
- Um investimento \\ - Trará retorno \\ longo prazo \\ Uma despesa
}

Fonte: Dados da pesquisa 2013

Em análise do gráfico acima, observa-se que a gestão de recursos humanos é um departamento de grande importância nas organizações, conclui-se que 100\% dos entrevistados veem esse setor como um investimento e que trará retorno a longo prazo.

Segundo Chiavenato (2010) Gestão de Pessoas é o departamento dentro da empresa, responsável por administrar e gerir o capital humano é uma área interdisciplinar que envolve vários conceitos de várias áreas. 
Segundo o autor, a gestão de recursos humanos sinaliza claramente que as organizações são constituídas por pessoas e dependem delas para chegar ao alcance dos seus objetivos e cumprir suas metas, pois uma das suas funções é a mediação entre colaborador e empregador.

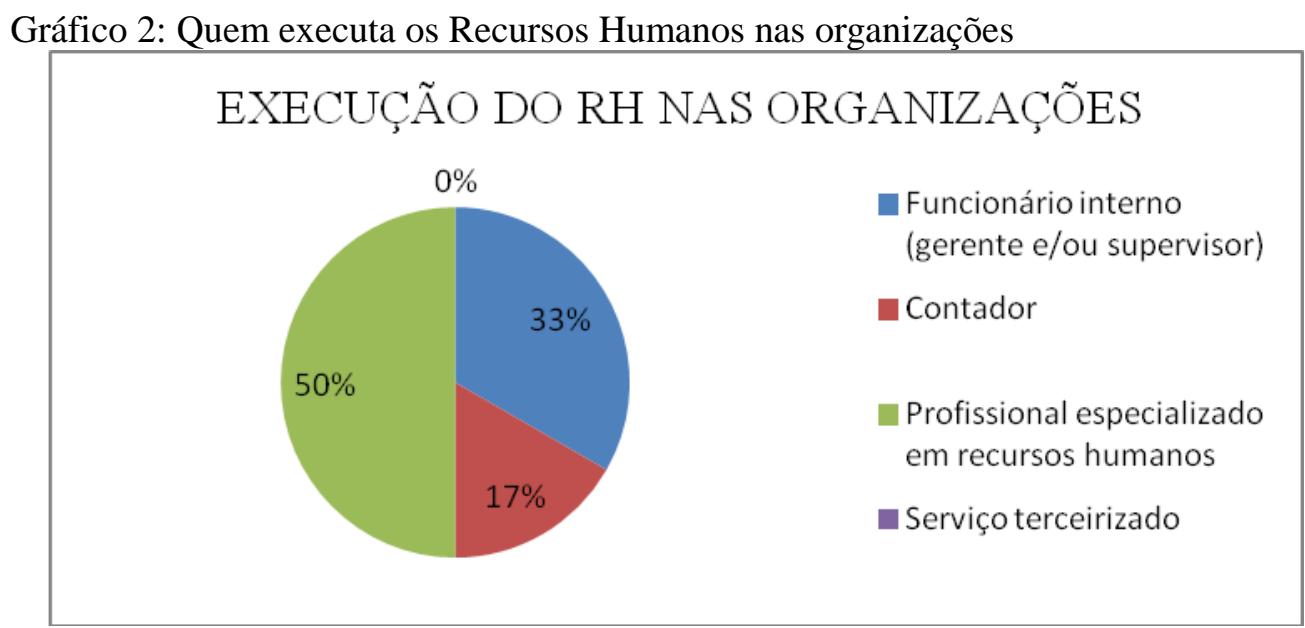

Fonte: Dados da pesquisa 2013

Verifica-se que 50\% das empresas entrevistadas dispõem de um profissional especializado na área de recursos humanos para execução das tarefas, sendo $33 \%$ executados por profissionais internos (gerente e/ou supervisor) dentro da organização e 17\% executado por um contador.

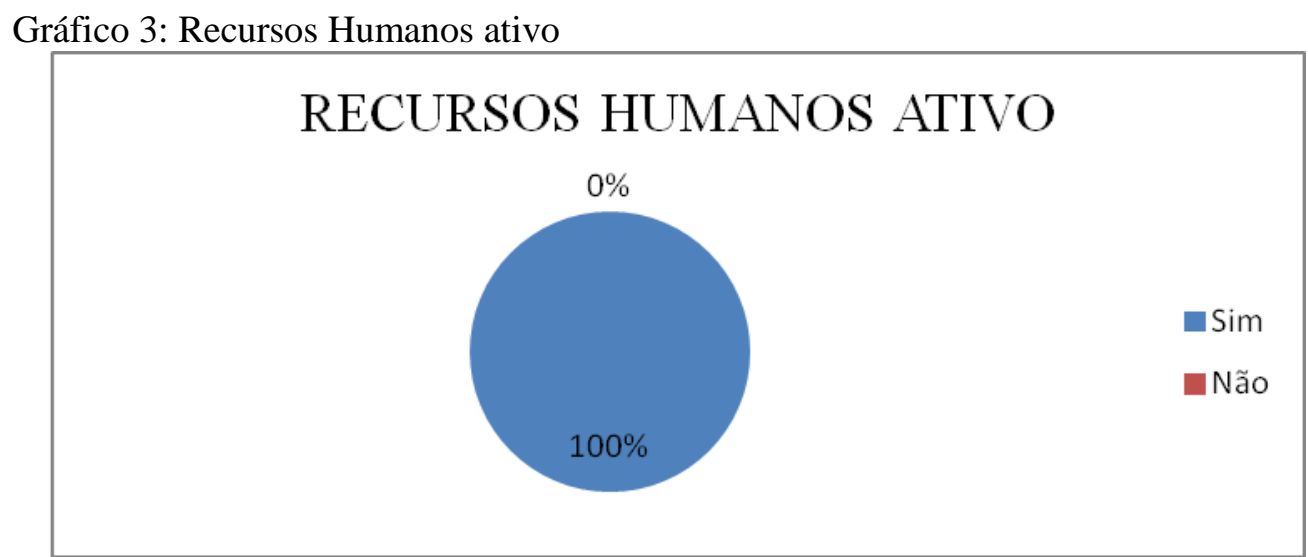

Fonte: Dados da pesquisa 2013

Como mostra o gráfico acima, percebe-se que $100 \%$ das empresas dizem possuir um departamento de recursos humanos ativo. Para Chiavenato (2010) o departamento de recursos humanos ativo, destaca as pessoas como recursos vivos, aptos a desenvolver seus talentos e não mais pessoas incapazes de pensar e agir. 
Gráfico 4: Como o Departamento de Recursos Humanos encontra-se

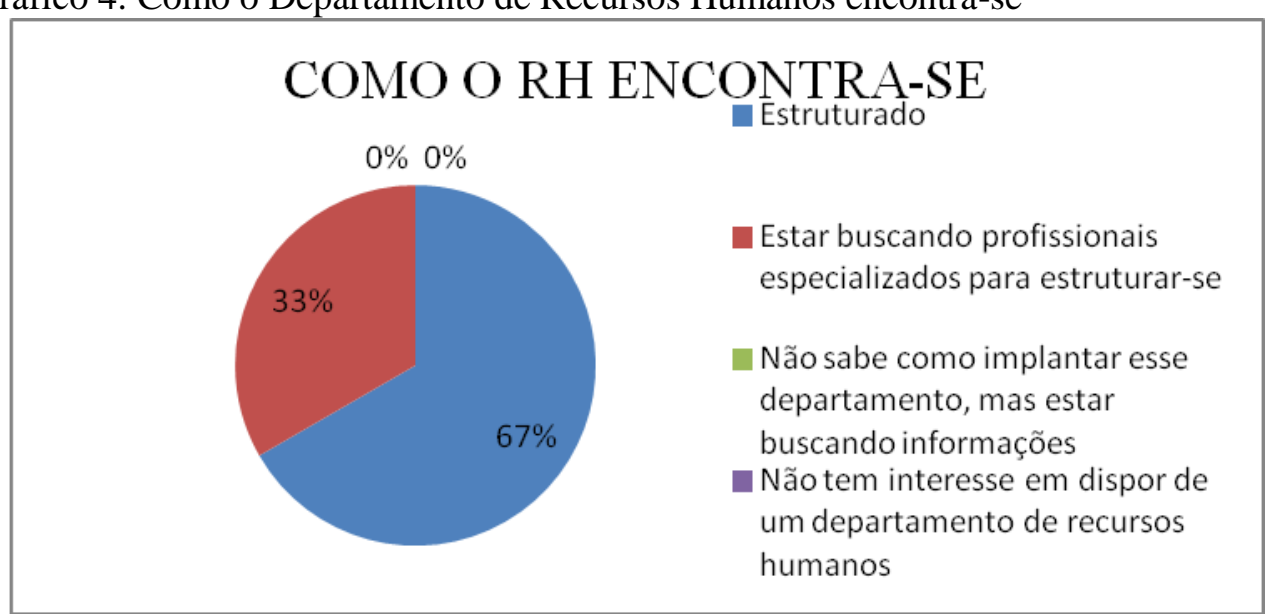

Fonte: Dados pesquisa 2013

Observando o gráfico a cima, pode-se perceber que 67\% das organizações possuem um rh estruturado, onde as práticas do rh são delegas a um profissional da área.

Para Chiavenato (2010) a estrutura da gestão de pessoas é formada por processos estratégicos que vai desde agregar, aplicar, recompensar, manter, desenvolver e monitorar pessoas. A gestão de recursos humanos é responsabilidade de linha e função de staff, que requer integração entre os especialistas da área com os gerentes de linha, para que possam desempenhar as funções organizacionais com êxito.

Gráfico 5: Funções ou atividades desempenhadas pelos recursos humanos na instituição

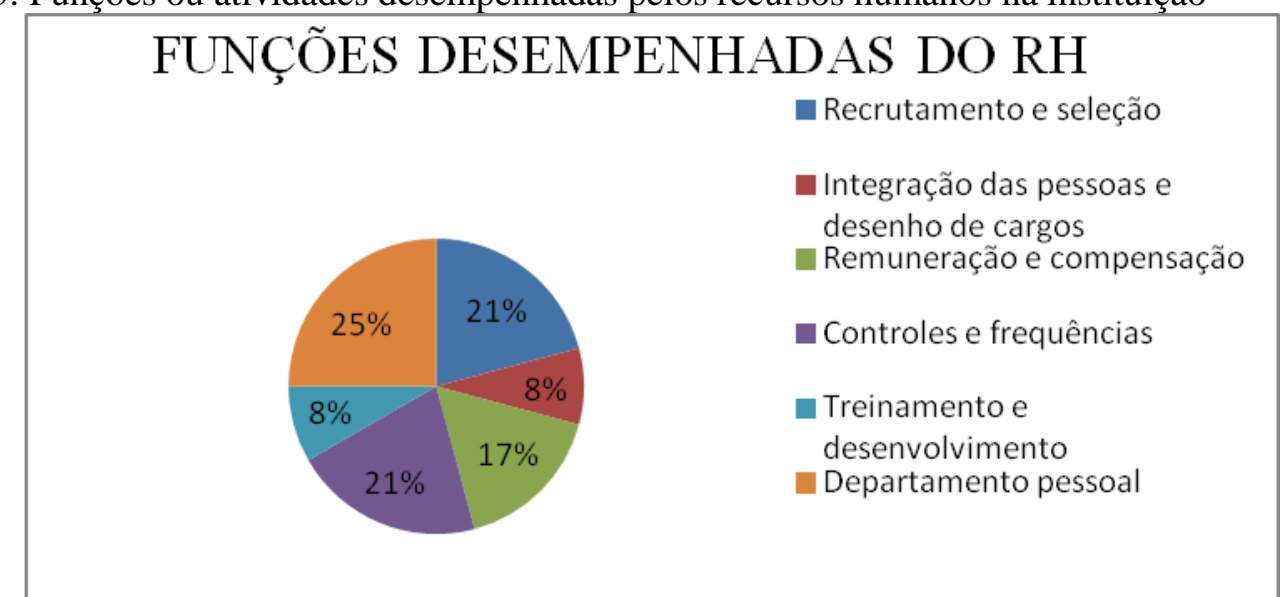

Fonte: Dados pesquisa 2013

Analisando o gráfico acima, pode-se afirmar que $25 \%$ das empresas ainda associam os recursos humanos a departamento de pessoal, onde $21 \%$ das empresas afirmam que as funções 
desempenhadas pelo rh são recrutamento e seleção e controles e frequências, $17 \%$ estão voltados à remuneração e compensação e apenas $8 \%$ investem em integração e treinamento e desenvolvimento das pessoas.

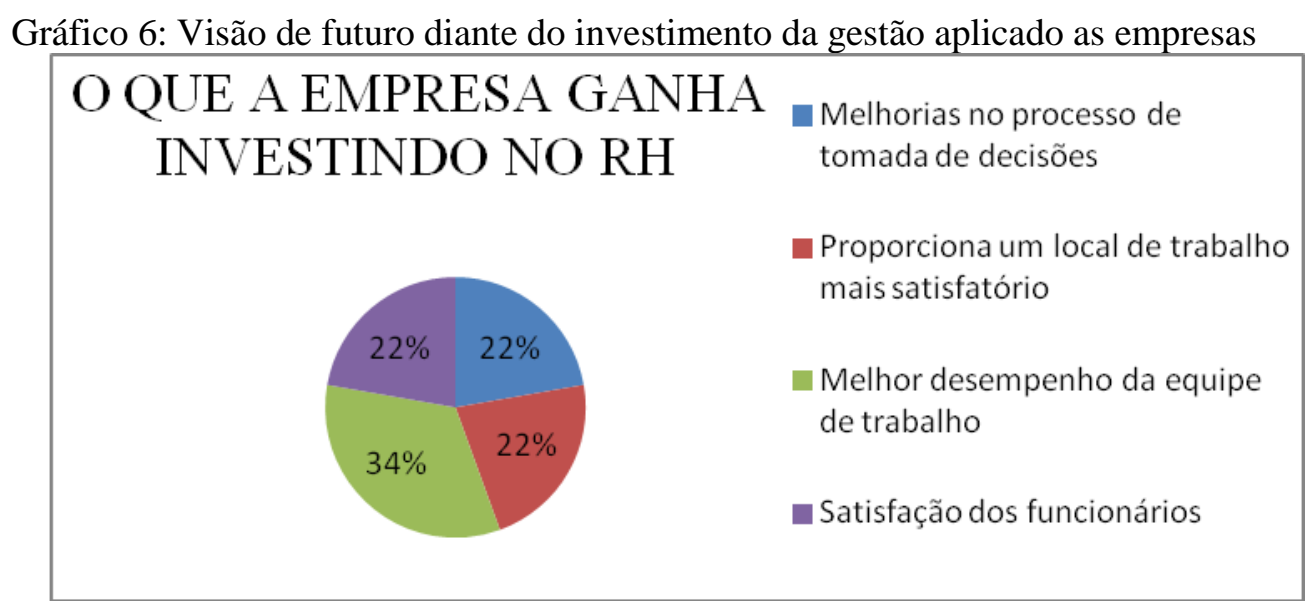

Fonte: Dados pesquisa 2013

Observando o gráfico acima, foi identificado que na visão dos empreendedores, investir na gestão de recursos humanos com $34 \%$ das respostas melhora o desempenho da equipe de trabalho, onde $22 \%$ afirmam que a empresa tende a melhorar os processos nas tomadas de decisões, proporcionar um local de trabalho satisfatório e maior satisfação dos funcionários.

Gráfico 7: O que a organização está fazendo para assegurar os talentos nas empresas

\section{COMO RETER OS TALENTOS NAS EMPRESAS}
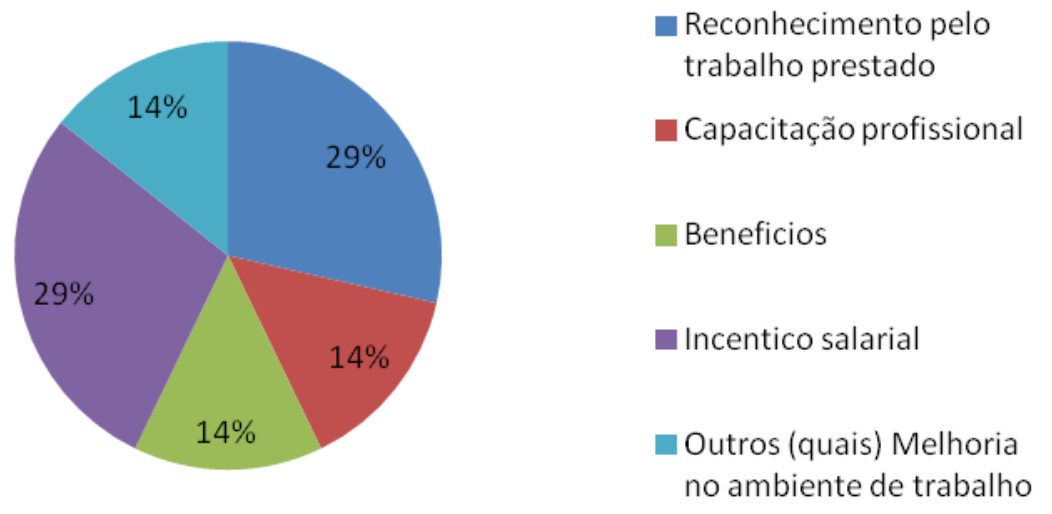

Fonte: Dados pesquisa 2013 
Em análise ao gráfico a cima, observa-se que as empresas estão cada vez mais buscando assegurar seus talentos dentro das organizações, onde $29 \%$ dos empreendedores entrevistados afirmam que a maneira mais eficaz para conseguir reter esses talentos é através do reconhecimento pelo trabalho prestado e incentivo salarial, outros $14 \%$ dizem que é necessário oferecer benefícios, capacitação profissional e melhoria no ambiente de trabalho.

Almeida (2009, p.3) observa que "além da capacitação, a retenção e desenvolvimento de profissionais talentosos devem ser preocupações constantes das organizações que possuem uma filosofia voltada para talentos". Reter os talentos de uma empresa é uma ferramenta importante para o sucesso da organização, saber valorizar e desenvolver o potencial das pessoas é hoje um grande diferencial nos negócios, buscando equipes cada vez mais qualificadas e com competências que agreguem vantagem competitiva pela disseminação do conhecimento e constante aprendizagem.

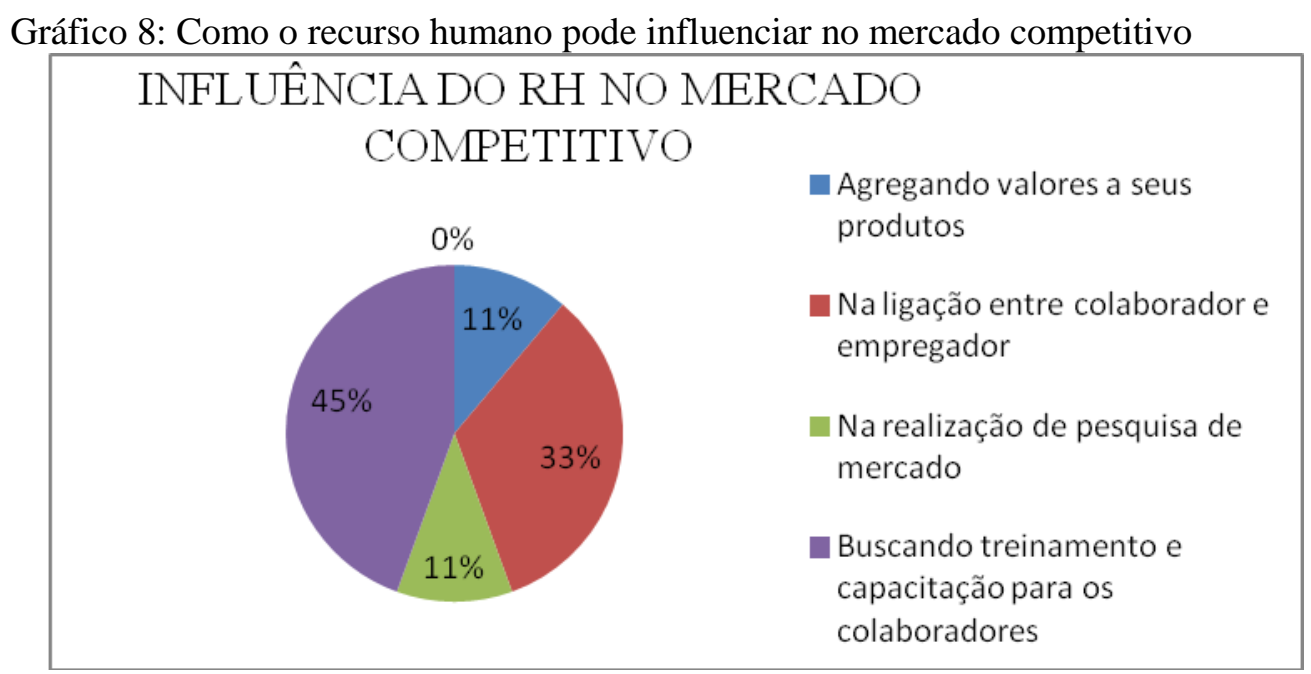

Fonte: Dados pesquisa 2013

Analisando o gráfico, percebe-se que $45 \%$ dos entrevistados dizem que dispor de um rh mais competitivo influencia o empregador a está buscando treinamento e capacitação para os colaboradores, $33 \%$ afirmam que ajuda na ligação entre colaborador e empreendedor e $11 \%$ que da suporte a pesquisa de mercado e agrega valores aos seus produtos e serviços.

Segundo Baze (2010) a gestão administrativa é hoje o principal fator competitivo para qualquer organização, tendo como maior desafio a aplicação de um tripé dentro de qualquer rh, sendo eles: atrair, reter e desenvolver seus colaboradores, portanto, consolidando essas três ferramentas a empresa agrega mais valor às suas atividades e processos.

O RH dos novos tempos é o grande diferencial dentro das organizações, sendo ele capaz de está sempre inovando e buscando capacitação e treinamentos para os talentos nas empresas, afinal, uma organização necessita de colaboradores capacitados e motivados. 
Gráfico 9: O maior desafio do empreendedor para implantar o rh nas empresas

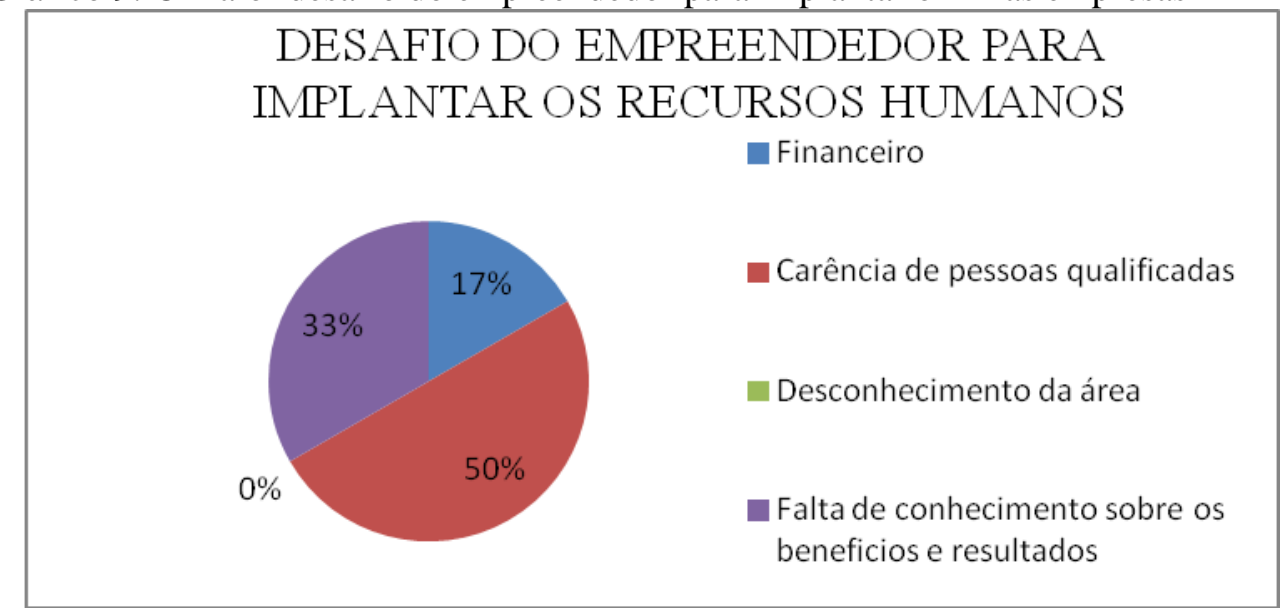

Fonte: Dados pesquisa 2013

Em análise do gráfico acima, é notório que os empreendedores encontram alguns desafios para que possam dispor de um recursos humanos ativo dentro das suas empresas, dentre os dados coletados, pode-se perceber que o maior desafio encontrado por eles é justamente a carência de pessoas qualificadas para trabalharem na área, segundo $50 \%$ dos dados coletados.

Analisando mais sobre a pesquisa, percebe-se que 33\% dos entrevistados afirmam não ter conhecimento sobre os benefícios e resultados que a gestão de pessoas agrega a instituição, enquanto $17 \%$ deles alegam não dispor desse recurso por questões financeiras, onde pode-se perceber que alguns empreendedores ainda veem como custo alto investir nesse setor.

\section{Considerações Finais}

O estudo proposto por este artigo foi à necessidade de identificar a estrutura e funcionamento do setor de recursos humanos no pólo calçadista de Juazeiro do Norte-CE. Diante dos argumentos apresentados acima, percebe-se que as empresas estão buscando cada vez mais investir em seus colaboradores.

Estes investimentos não devem ser feitos de maneira qualquer, é necessário que se busque adequar às necessidades das empresas e alinhada às necessidades dos seus colaboradores, pois ao serem respeitados e valorizados esses tendem a trabalhar mais motivados e consequentemente, gerando assim, mais produtividade.

Analisando o estudo, observa-se que os empreendedores seguem um ritmo de transformações, onde estão mudando a sua maneira de administrar, passaram a enxergar o valor que as pessoas agregam.

Id en lime Revista de Psicologia. Ano 7, No. 21, Novembroo/2013 - ISSN 1981-1179.

Edição eletrônica em http://idonline.emnuvens.com.br/id 
Diante dessas informações, é necessário destacar que os colaboradores não dependem só das organizações para tornarem talentos efetivos no seu local de trabalho, é necessário que se adequem as mudanças e busquem capacitação. As novidades surgem todos os dias, nos cercam por "todos os lados" e os profissionais precisam manter-se sempre atualizados com as inovações relacionadas à sua área e ao negócio da empresa em que atuam, pois o grande desafio das organizações ainda é a falta de profissionais aptos de competência e qualificação profissional.

A pesquisa apresenta dados importantes para sociedade e para as pessoas engajadas no mundo acadêmico, gerando informações onde terão maior visão do crescimento das indústrias calçaditas do cariri, tendo consciência de que esse setor está se desenvolvendo e gerando assim, mais oportunidades de investimentos e empregos.

Para os pesquisadores, poderem ter uma visão ampla de como encontra-se esse segmento, podendo observar que o setor cresce a cada dia e junto com ele cresce também a necessidade de está se adequando a esse novo mercado, estando sempre abertos a mudanças e inovações, para que possam estar aptos a adentrar a esse novo sistema de trabalho tão competitivo.

Conclui-se que, a maioria das empresas estão investindo mais nos seus processos e atentos a melhores condições de trabalho para os seus colaboradores, estão buscando informações para interagir melhor com a gestão de pessoas, pois a chave para o sucesso de qualquer organização é o seu capital humano. Onde os gestores garantem além de ferramentas importantes ao sucesso da organização, a possibilidade de atrair talentos e desenvolver aqueles que nela já estão em função das aprendizagens geradas nas trocas.

\section{Referências}

\section{ALMEIDA, W ALNICE. CAPACITAÇÃO E SELEÇÃO DE TALENTOS: COM FOCO EM COMPETÊNCIAS. 2. ED. SÃO PAULO: ATLAS S.A, 2010.}

BAZE, Frank, a importância da Gestão de Pessoas. Disponível em: 〈http://www.webartigos.com/artigos/a-importancia-do-rh-como-diferencial-competitivo-para-asorganizacoes-contemporaneas/42939/\#ixzz24IVZerfD> Publicado em: 17/jul./2010 Acesso em: 05 set. de 2012.

BIANCHI, M.P; ALBUQUERQUE, L.G. Efetividade de recursos humanos, Disponível em: www.ead.fea.usp.br, Acesso em: 31/mar/2013.

Id en line Revista de Psicologia. Ano 7, No. 21, Novembroo/2013 - ISSN 1981-1179.

Edição eletrônica em http://idonline.emnuvens.com.br/id 
CARVALHO, Renata, SEIXAS, Luís Jorge, Implantando o sistema de gestão de recursos humanos encontrado em: 〈http://www.apoenarh.com.br/implantando-sistema-de-gestao-de-rh>, Publicado em: 21/maio/2012. Acesso em: 16/jan./2013.

CHIAVENATO, Idalberto. Recursos humanos: o capital humano das organizações. 9. Ed. Rio de Janeiro: Elsevier, 2009.

CHIAVENATO, Idalberto. Administração de recursos humanos: fundamentos básicos 7, ed. Rio de Janeiro: Manole: 2007.

CHIAVENATO, Idalberto. Gestão de Pessoas: o novo papel dos recursos humanos nas organizações. 3. Ed. Rio de Janeiro: Elsevier, 2010.

Diário do Nordeste, Publicado em: 15 2009. Disponível em:<http://blogs.diariodonordeste.com.br/egidio/economia/juazeiro-do-norte-e-o-3\%C2\%BA-polocalcadista-do-pais/>Acesso em: 03/set/2012.

GIL, Antônio Carlos. Como elaborar projetos de pesquisa. 4. Ed. São Paulo: Atlas s.a, 2002.

LAKATOS, E.M.; MARCONI, M.A. Metodologia científica. 5. Ed. São Paulo: Atlas s.a, 2011.

LAKATOS, E.M.; MARCONI, M.A. Fundamentos da metodologia cientifica. 7. Ed. São Paulo: Atlas s.a, 2010.

Pesquisa da Deloitte aponta desafios e planos de investimento do empresariado brasileiro até 2015, Publicada em: $30 /$ $\operatorname{mar} / 2011$. $<$ https://www.deloitte.com/view/pt_BR/br/Conteudos/estudosepesquisas/1e7ca3393280f210VgnVCM 2000001b56f00aRCRD.htm> Acesso em: 16/jan./2013.

SALLES, Carlos Alberto. Como implantar o rh em uma empresa. Disponível em: http://www.administradores.com.br. Publicado em: 25/ago./2009. Acesso em: 09/abr./2013.

SILVA, Alessandri Campos Vilanova e. Processos de Gestão de pessoas. Disponível em: http://www.administradores.com.br/home/alessiv/blog. Publicado em: 28/ago./2009. Acesso em: 08/abril/2013. 
SINDINDÚSTRIA, Cariri notícia, Disponível em: Juazeiro do Norte-CE: INDÚSTRIA

CALÇADISTA Polo avança em tecnologia. Publicado em: 26/jun./2011. Acesso em: 30/05/2013.

STOCK, Fabiane, Implantando o Rh em pequenas empresas, Publicado em: 13/jul./2009.<http://www.artigonal.com/recursos-humanos-artigos/implantando-o-rh-em-pequenasempresas-1034724.html>, Acesso em: 2 1/jan./2013.

\section{Como citar este artigo (Formato ISO):}

SOUSA, M.A.T.; CAVALCANTE, S.M.M.; ALMEIDA NETO, J.L. As Novas Perspectivas da Gestão de Pessoas nas Indústrias do Polo Calçadista de Juazeiro do Norte-Ceará. Id on Line Revista de Psicologia, Novembro de 2013, vol.1, n.21, p. 115-132. ISSN 1981-1189. 